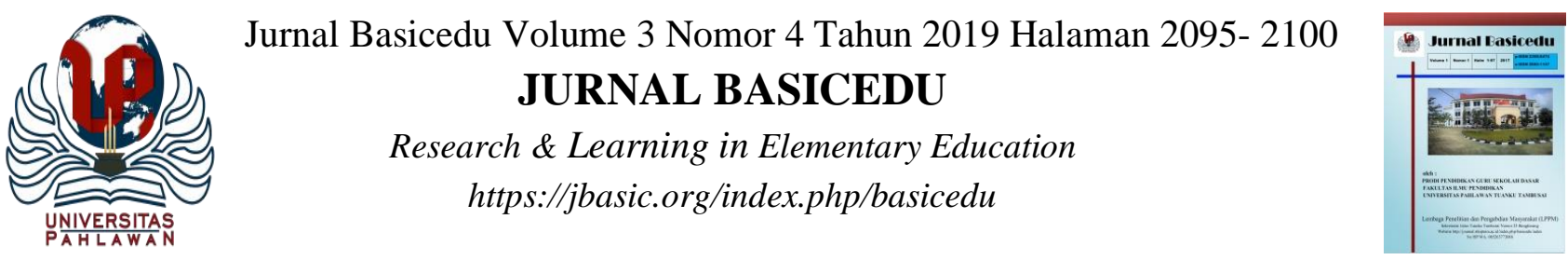

\title{
PENGARUH KUALITAS PELAYANAN DAN KECEPATTANGGAPAN TERHADAP MINAT BACA SISWA SD
}

\author{
Yulian Dinihari ${ }^{1}$,Aster Pujaning Ati ${ }^{2}$ \\ Universitas Indraprasta PGRI Jakarta, Jakarta, Indonesia ${ }^{1,2,3}$ \\ Email : : yulian.dinihari@unindra.ac.id ${ }^{1}$, , asterpujaningati@ymail.com ${ }^{2}$
}

\begin{abstract}
Abstrak
Minat baca siswa masih sangat minim. Pembelajaran dan teknik yang kurang tepat akan menambah kobosanan siswa untuk membaca dalam menambah wawasan . Guru dikelas cenderung mengajak siswa untuk membaca, tanpa memberikan trik dan cara membaca efektif dan bagaimana siswa menyukai membaca. Hal ini diperburuk dengan pelayanan membaca di berbagai tempat, seperti perpustakaan, taman bacaan, . Respon yang kurang atas keluhan dan jawaban dari pertanyaan pengunjung perlu di perbaiki dan ditingkatkan pelayananya. Metode penelitian ini menggunakan metode kuantitatif. Sebelum diolah , dengan SPSS 21 , data akan diuji normalitas dan homogenitas. Tujuan penelitan untuk mencari pengaruh pelayanan dan respon tanggap terhadap minat baca di taman bacaan manca Bekasi. Responden sebanyak 33 pengunjung siswa sekolah dasar. Hasil penelitian menunjukkan bahwa kualitas pelayanan berpengaruh terhadap minat baca, kecepatan tanggapan ( responsiveness) tidak berpengaruh terhadap minat baca, dan kualitas pelayanan dan kecepatan tanggapan berpengaruh terhadap minat baca. Pihak pengelola dapat meningkatkan kualitas pelayanan dengan cara menambah bahan bacaan digital dan mengadakan kompetisi membaca antar siswa.
\end{abstract}

Kata kunci : Kualitas Pelayanan, kecepattanggapan, Minat Baca

\begin{abstract}
Student reading interest is still very minimal. Inappropriate learning and techniques will increase students' readiness to read in adding insight. Teachers in class tend to invite students to read, without giving tricks and how to read effectively and how students like to read. This is exacerbated by reading services in various places, such as libraries, reading parks, etc. Lack of response to complaints and answers to questions visitors need to be improved and improved service. This research method uses quantitative methods. Before processing, with SPSS 21, the data will be tested for normality and homogeneity. The purpose of this research is to look for the effect of services and responsive responses to reading interest in Bekasi overseas reading parks. Respondents were 33 visitors of elementary school students. The results showed that the quality of service affects the interest in reading, the speed of response (responsiveness) does not affect the interest in reading, and the quality of service and the speed of response affect the interest in reading. The management can improve the quality of service by adding digital reading material and holding reading competitions between students.
\end{abstract}

Keywords: Service Quality, Response Responses, Reading Interest

@ Jurnal Basicedu Prodi PGSD FIP UPTT 2019

$\triangle$ Corresponding author:

Address : JL.Raya Gedong Jakarta Timur $\quad$ ISSN 2580-3735 (Media Cetak)

Email : $\underline{\text { unindra103@gmail.com }} \quad$ ISSN 2580-1147 (Media Online)

Phone 


\section{PENDAHULUAN}

Pada era digital yang serba cepat, manusia cenderung untuk dapat mengikuti informasi dengan instant. Teknologi informasi dan digital terus berkembang. Dan tak terasa semakin penting. Informasi yang cepat, harusnya diimbangi oleh minat baca yang cukup. Banyak lokasi yang dapat didatangi oleh para siswa ntuk membaca. Dintarannya taman bacaan yang terus berkompetisi dengan teknologi media sosial yangmenyediakan banyak bacaan. Hal tersebut membuat Taman bacaan harus memasang strategi yang tepat sebagai penyedia informasi agar Taman bacaan tidak ditinggalkan oleh masyarakat pemakainya. Dengan makin transparannya batas antara negara dan wilayah, maka suka atau tidak suka Taman bacaan harus menerima perkembangan teknologi informasi dan mengaplikasikannya ke dalam layanan-layanan Taman bacaan, sehingga kualitas pelayanan yang ada di taman bacaan akan meningkat. Yang dulu pelayanan Taman bacaan hanya dilakukan secara manual sekarang sudah menggunakan komputer baik dari sistem peminjaman, pengembalian sampai dengan penelesuran informasi. Membanjirnya informasi mengharuskan Taman bacaan untuk bisa selalu mengadopsi informasi informasi baru yang selalu berkembang untuk kepentingan masyarakat penggunanya. Sehingga adanya layanan internet di taman bacaan memang sangat diperlukan. Sebagai lembaga layanan informasi taman bacaan mempunyai prospek yang cukup luas dalam pembangunan. Taman bacaan sebagai sumber informasi diharapkan tidak hanya sekedar melayani masyarakat untuk mendapatkan informasi ilmu pengetahuan saja, akan tetapi taman bacaan diharapkan dapat mempertahankan eksistensinya sebagai lembaga pelayanan informasi serta dapat meningkatkan kualitas layanan yang ada. Hal tersebut akan dapat terlaksana apabila dudukung oleh pustakawan- pustakawan yang handal, yang tidak saja profesional dalam bidang ilmu Taman bacaan tetapi juga terampil dalam bidang ilmu pengetahuan lain yang dapat meningkatkan jati diri pustakawan dan tentunya untuk peningkatan kualitas layanan Taman bacaan. Dalam memberikan layanan kepada penggunanya Taman bacaan masih perlu belajar dan menengok lembaga lain seperti bank, hotel, remah sakit dan biro-biro jasa lain yang sama -sama memberikan jasa layanan kepada masyarakat. Untuk itu agar kesan pegawai taman bacaan galak, tidak ramah, sombong, angker tidak lagi disandang sebagai gelar yang selalu melekat pada penyelenggara Taman bacaan , maka perlunya diusahakan langkah-langkah perbaikan untuk peningkatan kualitas layanan Taman bacaan.

\section{METODE}

Jenis penelitian yang digunakan adalah metode survey. Suharsimi (2006) menyatakan sampel adalah sebagian atau wakil populasi yang diteliti. Teknik pengambilan sampel yang digunakan adalah teknik accidental random sampling. Teknik accidental random sampling adalah teknik pengambilan sampel secara kebetulan dimana semua anggota populasi mempunyai peluang yang sama untuk dijadikan anggota sampel. Sampel yang digunakan dalam penelitian ini ditetapkan sejumlah 33 responden, dengan tujuan untuk memperoleh sampel yang lebih representatif. Sampel ini merupakan sampel homogen yaitu terdiri dari pengunjung taman bacaan Manca Kota Bekasi pada hari senin sampai dengan jumat, dari berbagai umur dengan komposisi umur sebagai berikut :

Tabel 1. Jumlah responden 
2097 Pengaruh kualitas pelayanan dan kecepattanggapan terhadap minat baca siswa sekolah dasar- Yulian Dinihari, Aster Pujaning Ati

\begin{tabular}{l|llc} 
No & Umur & Pekerjaan & Jumlah \\
\hline 1 & 5 sd 6 tahun & Pelajar SD & 11 \\
2 & 6 sd 7 tahun & Pelajar SD & 12 \\
3 & 7 tahun keatas & Pelajar SD & 9 \\
\multicolumn{4}{c}{ Jumlah 33 responden }
\end{tabular}

Responden berkunjung ke taman bacaan.

Teknik pengambilan sampelnya juga menggunakan teknik random. Pengambilan data di SDN pekayon Kota Bekasi Bekasi. Variabel dalam penelitian ini adalah: Variabel terikat yaitu variabel yang nilainya dipengaruhi oleh variabel independen (Umar, 2002). Variabel terikat dalam penelitian ini adalah minat baca. Indikator dari minat baca $(\mathrm{Y})$. Variabel bebas yaitu variabel yang menjadi sebab terjadinya/terpengaruhnya variabel dependen (Umar, 2002). Variabel bebas dalam penelitian ini adalah: Variabel $\mathrm{X}_{1}$, yaitu kualitas pelayanan. Adapun indikator kualitas pelayanan $\left(\mathrm{X}_{1}\right)$ dan Variabel $\mathrm{X}_{2}$ yaitu kecepatan tanggapan, Variabel bebas kedua $\left(\mathrm{X}_{2}\right)$ dalam penelitian ini adalah kecepatan tanggapan).

Metode pengumpulan data dimaksudkan untuk memperoleh informasi yang relevan, akurat dan reliabel. Suharsimi (2006) mengemukakan bahwa metode dokumentasi adalah mencari data mengenai hal-hal atau variabel-variabel yang berupa catatan, transkrip, buku, jurnal, surat kabar, majalah dan sebagainya. Suharsimi (2006) mengungkapkan bahwa kuesioner adalah sejumlah pertanyaan tertulis yang digunakan untuk memperoleh informasi dari responden dalam arti laporan tentang pribadinya atau hal-hal yang ia ketahui. Dalam penelitian ini kuesioner digunakan untuk memperoleh informasi dan tanggapan dari pelanggan mengenai kualitas pelayanan, kecepatan tanggapan dan minat baca di Taman bacaan Manca. Kuesioner yang digunakan adalah kuesioner tertutup.
Skala yang digunakan dalam penyusunan kuesioner adalah skala ordinal atau sering disebut skala LIKERT, yaitu skala yang berisi lima tingkat preferensi jawaban (Ghozali, 2006). Lima tingkat preferensi jawaban yang digunakan dalam kuesioner penelitian ini yaitu: Sangat setuju, dengan skor 5; Setuju, dengan skor 4; Cukup setuju, dengan skor 3; Tidak setuju, dengan skor 2; Sangat tidak setuju, dengan skor 1. Analisis data yang digunakan adalah analisis deskriptif dan analisis regresi linear berganda menggunakan SPSS release 21.

\section{HASIL DAN PEMBAHASAN}

Berdasarkan pertanyaan yang merupakan variabel $\mathrm{X}_{1}$ setelah melalui proses pengolahan uji validitas dengan menggunakan korelasi pearson yang dinyatakan valid karena nilai korelasi yang dihasilkan pada korelasi diatas 0,3 (Azwar, 2000), ternyata hanya variabel K9 dan K10 yang tidak valid.

Tabel 2

Hasil Uji Validitas Variabel $\mathrm{X}_{1}$

\begin{tabular}{|l|l|l|}
\hline $\begin{array}{l}\text { Kuesioner } \\
\mathbf{X}_{1}\end{array}$ & $\begin{array}{l}\text { Korelasi } \\
\text { Pearson }\end{array}$ & Hasil Validitas \\
\hline VARK1 & 0,390 & Valid \\
\hline VARK2 & 0,760 & Valid \\
\hline VARK3 & 0,568 & Valid \\
\hline VARK4 & 0,530 & Valid \\
\hline VARK5 & 0,726 & Valid \\
\hline VARK6 & 0,496 & Valid \\
\hline VARK7 & 0,398 & Valid \\
\hline VARK8 & 0,347 & Valid \\
\hline VARK9 & 0,219 & Tidak valid \\
\hline VARK10 & 0,209 & Tidak valid \\
\hline
\end{tabular}

Semua pertanyaan yang merupakan variabel $\mathrm{X}_{2}$ setelah melalui proses pengolahan uji validitas dengan menggunakan korelasi pearson dinyatakan variabel I3, I4, I5, I6, I7, I9, dan I10 
2098 Pengaruh kualitas pelayanan dan kecepattanggapan terhadap minat baca siswa sekolah dasar- Yulian Dinihari, Aster Pujaning Ati

yang valid, karena nilai korelasi yang dihasilkan pada korelasi diatas 0,3 (Azwar, 2000).

Tabel 3

Hasil Uji Validitas Variabel $\mathbf{X}_{2}$

\begin{tabular}{|l|l|l|}
\hline $\begin{array}{l}\text { Kuesioner } \\
\mathbf{X}_{2}\end{array}$ & $\begin{array}{l}\text { Korelasi } \\
\text { Pearson }\end{array}$ & $\begin{array}{l}\text { Hasil } \\
\text { Validitas }\end{array}$ \\
\hline VARI1 & 0,008 & TidakValid \\
\hline VARI2 & 0,295 & TidakValid \\
\hline VARI3 & 0,587 & Valid \\
\hline VARI4 & 0,567 & Valid \\
\hline VARI5 & 0,435 & Valid \\
\hline VARI6 & 0,625 & Valid \\
\hline VARI7 & 0,652 & Valid \\
\hline VARI8 & 0,254 & TidakValid \\
\hline VARI9 & 0,353 & Valid \\
\hline VARI10 & 0,535 & Valid \\
\hline VARI11 & 0,201 & TidakValid \\
\hline VARI12 & 0,017 & TidakValid \\
\hline VARI13 & 0,258 & TidakValid \\
\hline VARI14 & 0,275 & TidakValid \\
\hline
\end{tabular}

Semua pertanyaan yang merupakan variabel Y setelah melalui proses pengolahan uji validitas dengan menggunakan korelasi pearson dinyatakan valid seluruh kuesioner, karena nilai korelasi yang dihasilkan pada korelasi di atas 0,3 (Azwar, 2000).

Tabel 4

Hasil Uji Validitas Variabel Y

\begin{tabular}{|l|l|l|}
\hline $\begin{array}{l}\text { Kuesioner } \\
\text { Y }\end{array}$ & $\begin{array}{l}\text { Korelasi } \\
\text { Pearson }\end{array}$ & $\begin{array}{l}\text { Hasil Uji } \\
\text { Validitas }\end{array}$ \\
\hline VARKA1 & 0,558 & Valid \\
\hline VARKA2 & 0,760 & Valid \\
\hline VARKA3 & 0,654 & Valid \\
\hline VARKA4 & 0,790 & Valid \\
\hline VARKA5 & 0,676 & Valid \\
\hline VARKA6 & 0,683 & Valid \\
\hline
\end{tabular}

Semua variabel pertanyaan dari subvariabel $\mathrm{X}_{1}, \mathrm{X}_{2}, \mathrm{X}_{3}$, dan $\mathrm{X}_{4}$ sudah memenuhi hasil uji reliabilitas dengan nilai cronbach alpha lebih besar dari 0,6 , 1) Hasil Uji Reliabilitas Variabel $\mathrm{X}_{1}$ dengan nilai cronbach alpha $0.745,2$ ) Hasil Uji Reliabilitas Variabel $\mathrm{X}_{2}$ dengan nilai cronbach alpha 0.810 .

Semua variabel pertanyaan dari variabel Y sudah memenuhi hasil uji reliabilitas dengan nilai cronbach alpha lebih besar dari 0,6 (Nunnally, 1969 dalam Ghozali, 2007). Hasil Uji Reliabilitas variabel Y dengan nilai cronbach alpha 0.737 . Berdasarkan tabel 7 di bawah ini menunjukkan nilai sig. 0,048 (lebih kecil dari $\alpha=0,05$ ), artinya kualitas pelayanan berpengaruh terhadap minat baca pada $\alpha=0,05$ (tingkat kesalahan 5\%).

Tabel 5

\section{Coefficients $^{\mathrm{a}}$}

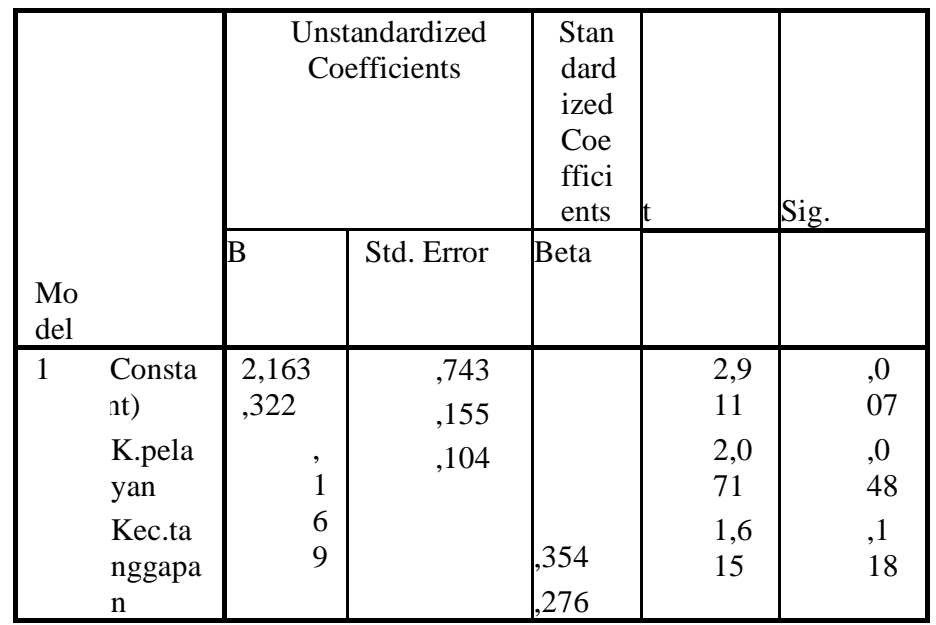

Berdasarkan tabel 7 di atas menunjukkan nilai sig. 0,118 (lebih besar dari $\alpha=$ 0,05), artinya kecepatan tanggapan tidak berpengaruh terhadap minat baca pada $\alpha=0,05$ (tingkat kesalahan 5\%). Berdasarkan tabel 9 menunjukkan bahwa nilai sig. 0,037 (lebih kecil dari $\alpha=0,05)$, artinya kualitas pelayanan dan kecepatan tanggapan berpengaruh terhadap minat baca pada $\alpha=0,05$ (tingkatkesalahan 5\%). Besarnya pengaruh kualitas pelayanan dan kecepatan tanggapan terhadap minat baca dapat 
2099 Pengaruh kualitas pelayanan dan kecepattanggapan terhadap minat baca siswa sekolah dasar- Yulian Dinihari, Aster Pujaning Ati

dilihat pada nilai adjusted $R$ square sebesar $15,8 \%$ yang disajikan pada tabel 8 .

Tabel 6

Model Summary

\begin{tabular}{|l|l|l|l|l|}
\hline Model & R & $\begin{array}{l}\mathrm{R} \\
\text { Square }\end{array}$ & $\begin{array}{l}\text { Adjusted } \\
\mathrm{R} \\
\text { Square }\end{array}$ & $\begin{array}{l}\text { Std. } \\
\text { Error of } \\
\text { the } \\
\text { Estimate }\end{array}$ \\
\hline 1 &, $465^{\mathrm{a}}$ &, 216 &, 158 &, 33666 \\
\hline
\end{tabular}

a. Predictors: (Constant),K.Pelayanan , Kec.tanggapan

\section{Tabel 9}

ANOVA $^{b}$

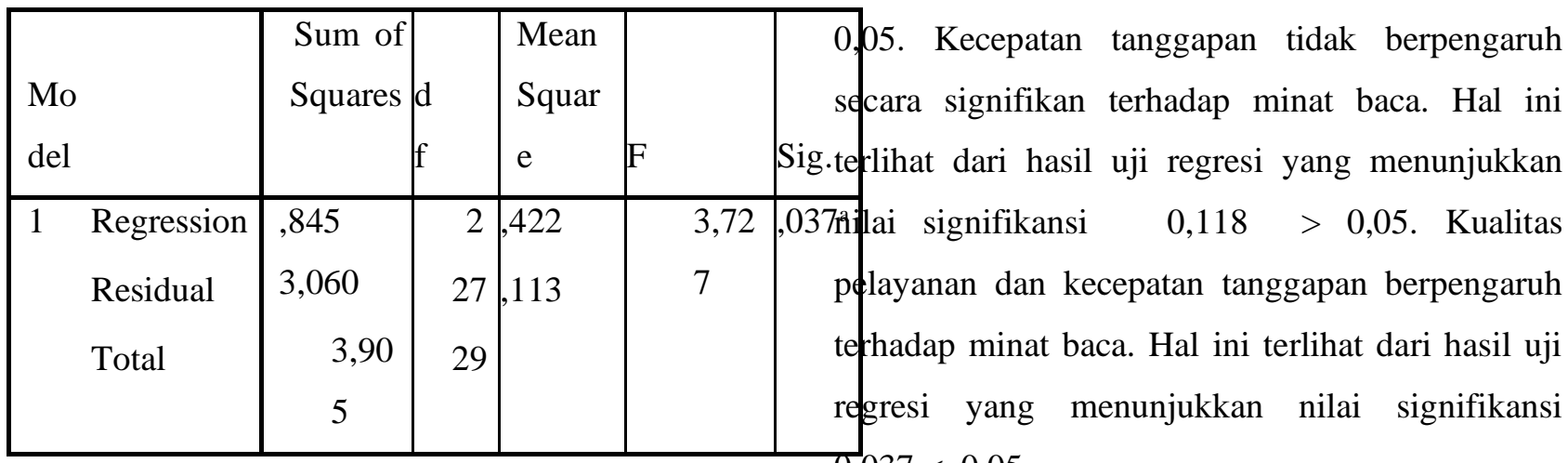

a. Predictors: (Constant), K.Pelayanan,

kec.tanggapan

b. Dependent Variable: minat baca

Hasil pengujian hipotesis ini menunjukkan bahwa kualitas pelayanan berpengaruh terhadap minat baca dilihat nilai sig. 0,048 (lebih kecil dari $\alpha=0,05$ ). Hal ini berarti bahwa kualitas pelayanan dapat dicapai jika para siswa memiliki minat baca yang baik. Hal ini sesuai dengan penelitian Firdiyanto.D ( 2012 ) yang menyatakan kualitas pelayanan petugas perpustakaan berpengaruh terhadap minat baca, sebesar 48\%. Hasil pengujian hipotesis ini menunjukkan bahwa kecepatan tanggapan tidak berpengaruh terhadap minat baca, dapat dilihat dari nilai sig. 0,118 (lebih besar dari $\alpha=0,05$ ). Hal ini sesuai dengan penelitian Afifuddin $\mathrm{M}($ 2009) yang menyatakan bahwa , kecepatan tanggapan menempati urutan paling bawah dalam pernyataan kepuaasan pelanggan, disbanding faktor lain seperti, empati, reabilitas dan yang lainnya. Hasil pengujian hipotesis ini menunjukkan bahwa kualitas pelayanan dan kecepatan tanggapan mempunyai pengaruh terhadap minat baca, dapat dilihat dari nilai sig. 0,037 (lebih kecil dari $\alpha=0,05$ ).

\section{SIMPULAN}

Berdasarkan hasil pengujian hipotesis, diperoleh kesimpulan penelitian sebagai berikut: Kualitas pelayanan berpengaruh secara signifikan terhadap minat baca. Hal ini terlihat dari hasil uji regresi yang menunjukkan nilai signifikansi 0,048 < $0,037<0,05$.

\section{DAFTAR PUSTAKA}

Ati, A. P., \& Widiyarto, S. (2019). Pembinaan Karakter Melalui Kegiatan Membaca Kritis Pada Siswa SMP Kota Bekasi. MATAPPA: Jurnal Pengabdian Kepada Masyarakat, 2(1), 39-42.

Azwar, Saifuddin. 2000. Reliabilitas dan Validitas. Yogyakarta: Pustaka Pelajar.

Frediyanto.D. 2012. Pengaruh fasilitas perpustakaan dan Pelayanan pustakawan Terhadap Minat Baca Masyarakat di perpustakaan daerah Kabpaten Boyolali

Ghozali, Imam. 2007. Aplikasi Analisis Multivariate dengan Program SPSS. Cetakan keempat. Badan Penerbit Universitas Diponegoro: Semarang

Kotler.Philip,2002. Manajemen Pemasaran,Pt Prehalindo : Jakarta

Hardianto, D. (2011). Studi tentang minat baca mahasiswa Fakultas Ilmu Pendidikan UNY. Majalah Ilmiah Pembelajaran, 7(1). 
SUPRANTO, J. 2006. Pengukuran Tingkat Minat baca: untuk menaikkan pangsa pasar. Jakarta: Rineka Cipta.

Widiyarto, S. (2017). Peranan Soft Skill dan Minat Baca Terhadap Kemampuan Menulis Eksposisi Mata Pelajaran Bahasa Indonesia. Semantik, 6(2), 31-38

Suyana, N., Ati, A. P., \& Widiyarto, S. (2019). Metode Partisipatori untuk Meningkatkan Kemampuan Menulis Argumentasi Pada Siswa MTs Nurul Hikmah Kota Bekasi. Linguista: Jurnal Ilmiah Bahasa, Sastra, dan Pembelajarannya, 2(2), 80-86

Indarwati, D., Wahyudi, W., \& Ratu, N. (2014). Peningkatan Kemampuan

Pemecahan Masalah Matematika Melalui Penerapan Problem Based Learning Untuk Siswa Kelas V Sd. Satya Widya, 30(1), 1727.

Fadhilaturrahmi, F. (2018). Pengaruh Pembelajaran Kooperatif Tipe STAD Dan GI terhadap Peningkatan Kemampuan Koneksi Matematik Siswa Sekolah Dasar. Jurnal Basicedu, 2(2).

Kementerian Pendidikan Dan Kebudayaan: Direktorat Jenderal Pendidikan Dasar Direktorat Pembinaan Sekolah Dasar Nurfajriyah, D. N., Aeni, A. N., \& Jayadinata, A. K. (2016). Pengaruh Model Problem Based Learning Terhadap Kemampuan Berpikir Kreatif Siswa Pada Materi Pesawat Sederhana. Jurnal Pena Ilmiah, 1(1), 251260.

Rahmadani, N., \& Anugraheni, I(2017). Peningkatan Aktivitas Belajar Matematika Melalui Pendekatan Problem Based Learning Bagi Siswa Kelas $4 \quad S d$. Scholaria Jurnal Pendidikan Dan Kebudayaan, 7(3), 241-250.

Rudyanto, H. E. (2016). Pengembangan Kreativitas Siswa Sekolah Dasar Melalui Pembelajaran Matematika Open-Ended. Premiere Educandum Jurnal Pendidikan Dasar Dan Pembelajaran, 3(02).

Utami Munandar. 2009. Mengembangkan Bakat Dan Kreativitas Anak Sekolah.

Jakarta: Gramesia Widiasarana Indonesia.

Wahyuni, S. (2014). Peningkatan Keaktifan Dan Hasil Belajar Ips Melalui Model Group Investigation (Gi) Pada Siswa Kelas Vi Sdn
Bandung, Wonosegoro. Scholaria Jurnal Pendidikan Dan Kebudayaan, 4(3), 97-106

Wardani, N. S. (2011). Upaya Meningkatkan Kreativitas Siswa Dalam Pembelajaran Ips Sd Melalui Diskusi kelompok.

Winarni, E. W., Dadi, S., \& Lusa, H. (2017). Pengaruh Pembelajaran Tematik Terpadu Menggunakan Discovery Learning Terhadap Pengetahuan Siswa Sekolah Dasar Tentang Peninggalan Sejarah. Jurnal Pendidikan Dasar. 